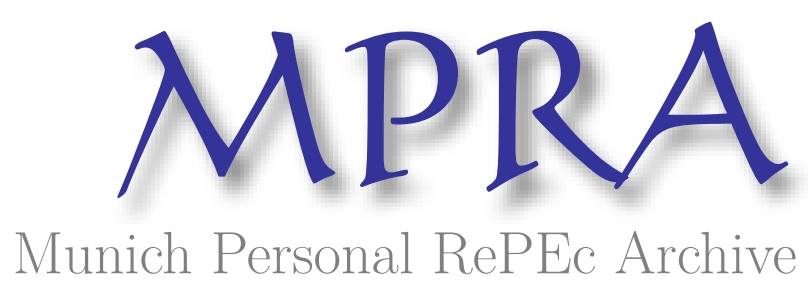

\title{
Aggregate impacts of recent U.S. natural gas trends
}

Arora, Vipin

11 January 2013

Online at https://mpra.ub.uni-muenchen.de/43708/

MPRA Paper No. 43708, posted 11 Jan 2013 14:46 UTC 


\title{
AGGREGATE IMPACTS OF RECENT U.S. NATURAL GAS TRENDS ${ }^{*}$
}

\author{
Vipin Arora \\ U.S. Energy Information Administration
}

\begin{abstract}
Predictions about the macroeconomic impacts of recent U.S. natural gas trends vary widely. I re-evaluate the possible effects on U.S. economic activity using a standard general equilibrium model. Within this framework I show that increases in natural gas supply result in small-tomoderate economic gains, even with unemployment or under-utilized capital. Subsequent rises in economy-wide productivity are the key to magnifying the economic impacts of greater natural gas supply and resources. The 1995-2000 period, where U.S. productivity growth was driven by information technology, is a good starting point for comparing how American productivity may evolve because of natural gas.
\end{abstract}

JEL Classification: D24, E17, E27, Q43

Keywords: Natural gas, general equilibrium, unemployment, variable capacity, shale, productivity

\footnotetext{
${ }^{*}$ The analysis and conclusions expressed here are those of the author and not necessarily those of the U.S. Energy Information Administration.

${ }^{\dagger}$ I have benefitted from the comments and suggestions of Alan Beamon, John Conti, David Daniels, Thomas Lee, Jozef Lieskovsky, Elizabeth Sendich, Kay Smith, and Russell Tarver.
} 


\section{Introduction}

Annualized U.S. natural gas production increased nearly 5\% each month from 2007 through the middle of 2012. These increases were driven by the application of two existing technologies in combination, hydraulic fracturing and horizontal drilling, to extract unconventional natural gas,

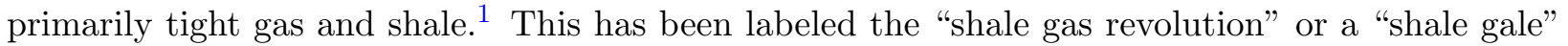
because of the prospects that such trends will continue into the future, driven by gains in shale gas production and enormous American shale gas resources. Several reports have attempted to quantify the potential economic benefits of this greater natural gas production (and resource base), resulting in a range of estimates. However, the studies differ among many dimensions and most use detailed frameworks which are estimated based on historical data.

In this paper I evaluate the macroeconomic impacts of recent and forecast U.S. natural gas trends in a standard general equilibrium framework. My primary goal is to show that the size of these economic impacts depends upon how economy-wide productivity evolves. That is, the medium-to-long-term economic impacts of gains in natural gas production and resources depend upon whether or not these lead to innovations in the broader economy. This simple observation is missing from much recent commentary and analysis. I attempt to put the hypothetical productivity impacts of the shale gas revolution into a historical perspective by briefly reviewing productivity trends, and then speculating on how important it might be for economy-wide productivity. My model also highlights that while under-utilized capital and labor can magnify the economic impacts of natural gas production increases, so can investment and hiring costs in the broader economy reduce such impacts.

Empirical work on the macroeconomic impacts of the U.S. natural gas market is limited. Kliesen (2006) finds that natural gas prices have historically been unable to predict total U.S. industrial production. These results are confirmed by Arora and Lieskovsky (2012), although they show that it is natural gas supply that impacts U.S. economic activity, not necessarily the price. More recent reports that attempt to quantify the impacts of increased unconventional natural gas production and resources are primarily model-based. Using the Global Insight U.S. Macro model in conjunction with the IMPLAN industry model, IHS (2011) estimate shale gas will contribute $\$ 118$ billion to the U.S. economy in 2015 , rising to $\$ 231$ billion by 2035 . And the same study finds that the shale gas industry itself will support over 1.6 million jobs in 2035, compared with 600,000 in 2010.

CitiGPS (2012) estimate real GDP gains of 2-3\% by 2020 due to increases in unconventional natural gas production, resulting in the creation of 2.7-3.6 million new jobs. This is higher than the estimated 835,000-1.6 million new jobs projected in 2017 by ICF (2012), who also forecast GDP increases of $\$ 167-\$ 245$ billion by the same year. The results reported in CitiGPS (2012) appear to be from a macroeconometric model, while those in ICF (2012) use a bottom-up approach which includes the IMPLAN industry model. ${ }^{2}$

I take a different approach and construct a general equilibrium model, and then extend it with under-utilized capital and unemployment. Final goods are produced by capital services and labor,

\footnotetext{
${ }^{1}$ Unconventional natural gas refers to natural gas which is trapped in source rock, as opposed to conventional natural gas that has migrated from source rock. Tight gas is natural gas which is trapped in sandstones, and shale gas is natural gas trapped in shale formations (fine-grained sedimentary rocks).

${ }^{2}$ Several related studies consider economic impacts on specific states or industries. Kinnaman (2010) (which reviews two state-level studies) and IHS (2012) focus on state level economic impacts; PWC (2011) study the U.S. manufacturing sector; and PWC (2012) estimate impacts on the U.S. chemicals industry.
} 
and capital services depend upon energy and capital. Energy is produced by combining capital with an aggregate of energy resources, and these energy resources are a composite between natural gas and other primary energy sources. The model is augmented with two shocks, a standard technology shock on final goods production and a natural gas supply shock. The results are summarized in different impulse responses to each shock.

The first experiment shows that the responses of model variables to a technology shock are consistent with other closed-economy real business cycle models. Impulse responses to the natural gas supply shock lead to small or moderate increases in GDP. The benefits of rising supply are concentrated in the energy sector, which is relatively small compared to the rest of the economy. Because of this even large increases in natural gas supply do not multiply into the broader economy. When under-utilized capital and labor are added the response of GDP to natural gas supply increases is larger, but still moderate in terms of its overall impact. In both cases the economic benefits are driven primarily by increases in investment, as additional natural gas raises the value of capital.

I then show that the economic impacts of natural gas supply shocks can be substantially multiplied if they also result in economy-wide productivity enhancements. This can occur if firms and governments invest and innovate based on the perception that natural gas supplies are abundant and natural gas prices will remain relatively low compared with other primary energy sources. The economic impacts of natural gas supply shocks can also be reduced due to the costs of investment or hiring. Although these costs may reduce natural gas supply increases themselves, the macroeconomic impacts of such supply increases are limited by investment and hiring costs in the broader economy.

The key result of the paper is that subsequent economy-wide productivity rises are necessary for the shale gas revolution to have a large and sustained impact on U.S. economic growth, i.e. to be the "game-changer" of popular lore. For example, the model suggests that a $5 \%$ increase in natural gas production can lead to an increase of up to $\$ 40$ billion in the first year, based on 2011 real U.S. GDP. Depending on how large GDP impacts are in subsequent years, such production trends are consistent with the studies that find small-to-moderate economic impacts discussed above.

The model cannot reproduce the more ambitious GDP growth projections discussed above solely with increases in natural gas supply. Rather, these large gains are possible only with subsequent economy-wide productivity increases. The model predicts that a $5 \%$ increase in natural gas production which leads to a $0.25 \%$ increase in total factor productivity can increase GDP by up to $\$ 65$ billion in the first year, based on 2011 U.S. GDP. While this $0.25 \%$ increase is illustrative, the overall impacts depend upon the magnitude and duration of productivity responses to natural gas. In fact, if the responses are large enough the estimates discussed above could potentially be too low.

To better understand how productivity may change because of additional unconventional natural gas production and resources I next review historical productivity trends. I argue that productivity gains due to the shale gas revolution will look less like the great inventions of the late 19th and early-20th centuries, and will be more comparable to the period from 1995 to 2000 characterized by advances in information technology. This is because the great inventions transformed everyday life, from the incorporation of electricity and indoor sanitation into American homes to the implications of the internal combustion engine. 
It is extremely unlikely that the innovations which follow greater natural gas production and resources can have this type of impact. But they may have an impact similar to that of information technology during the late-1990s, whereby productivity rises specific to relatively small sectors of the U.S. economy contributed a large amount to overall productivity growth. Such productivity gains are ongoing in many different sectors and plausible in others, for example mining, transportation and warehousing, construction, utilities, agriculture, and manufacturing. The question that remains is how big such changes will be and how long they may last.

\section{The Model}

The basic building block is a closed economy real business cycle model with full capital utilization and full employment. This baseline model is extended by adding variable capital utilization as in Greenwood et al. (1988) and unemployment as in Gali (2010). The full model with both variable capital utilization and unemployment is outlined below.

The economic environment has households that work, save, and consume and firms which produce intermediate and final goods. To produce final goods, firms use a combination of labor and capital services. These capital services are a combination of capital and energy, and energy is produced by combining different capital with an aggregate of energy resources. Energy resources are a composite between natural gas and other primary energy sources (coal, oil, etc.), all of which are in fixed supply. The degree to which there is substitution between natural gas and these other primary energy sources, between capital and the energy resource aggregate, and between energy and capital are governed by three different elasticities of substitution.

The capital stock used to produce final goods is not fully utilized, and can be varied. There is also unemployment in this model economy. Households choose the amount of labor to supply subject to a cost of labor market participation, and firms choose their labor demand subject to a hiring cost. Both of these costs lead to a surplus associated with employment, which is split between the consumer and firm according to a Nash bargaining protocol each period that determines the wage.

The dynamics in the economy are driven by two different shocks. There is a standard real business cycle technology shock on final goods production and a shock on natural gas resources (a natural gas supply shock). These processes induce a stochastic event, $s_{t}$, in each period $t$. The history of events up to and including $t$ is denoted by $s^{t}=\left(s_{o}, s_{1}, \ldots, s_{t}\right)$. The initial realization, $s_{o}$, is known. All equilibrium prices and allocations are a function of these histories, but the dependence will be suppressed throughout the paper for simplicity.

\subsection{Consumers}

A stand-in household represents all consumers in the economy. This household chooses consumption $\left(C_{t}\right)$, employment $\left(N_{t}\right)$, capital stock in capital services $\left(K_{s, t+1}\right)$, capital stock in energy $\left(K_{e, t+1}\right)$, and the capital utilization rate $\left(T_{t}\right)$ as to maximize expected utility:

$$
\max _{\left\{C_{t}, N_{t}, K_{s, t+1}, K_{e, t+1}, T_{t}\right\}_{t=0}^{\infty}} \mathbb{E}_{t}\left\{\sum_{t=0}^{\infty} \beta^{t} \frac{C_{t}^{1-\sigma_{c}}}{1-\sigma_{c}}+\xi_{0} \frac{\left(1-L_{t}\right)^{1-\xi}}{1-\xi}\right\}
$$


in this expression $L_{t}$ is an index of total time devoted to work, $\beta$ is the discount factor, $\sigma_{c}$ the coefficient of relative risk aversion (CRRA), $\xi$ is a parameter which determines the labor supply elasticity, and $\xi_{0}$ is a parameter which determines labor supply. The time devoted to work can be divided between the fraction of household members employed and unemployed:

$$
L_{t}=N_{t}+\kappa U_{t}
$$

where $N_{t}$ is the fraction of household members who are employed, and the $U_{t}$ is the fraction unemployed and looking for work. The parameter $\kappa$ quantifies the disutility generated by unemployment. Employment evolves over time according to:

$$
N_{t}=\left(1-\delta_{n}\right) N_{t-1}+x_{t} U_{t}^{o}
$$

in this equation $\delta_{n}$ is the separation rate for workers, $x_{t}$ is the job finding rate, and $U_{t}^{o}$ is the fraction of household members who are unemployed and looking for work at the beginning of period $t$. This also gives:

$$
U_{t}=\left(1-x_{t}\right) U_{t}^{o}
$$

The household is subject to a budget constraint:

$$
C_{t}+I_{s, t}+I_{e, t}=w_{t} N_{t}+r_{s, t} T_{t} K_{s, t}+r_{e, t} K_{e, t}+r_{g, t} N G_{t}+r_{o, t} O_{t}+\pi_{t}
$$

$I_{t}$ is investment, $N G_{t}$ the stock of natural gas (owned by the consumer), $O_{t}$ the stock of other primary energy sources, $w_{t}$ is the wage, the various $r_{t}$ are rates of return to capital and each energy resource, and $\pi_{t}$ is firm profits. Investment in each type of capital evolves according to:

$$
\begin{gathered}
I_{s, t}=K_{s, t+1}-\left(1-\delta_{s, t}\right) K_{s, t}+\frac{\phi_{s}}{2}\left(K_{s, t+1}-K_{s, t}\right)^{2} \\
I_{e, t}=K_{e, t+1}-\left(1-\delta_{e}\right) K_{e, t}+\frac{\phi_{e}}{2}\left(K_{e, t+1}-K_{e, t}\right)^{2}
\end{gathered}
$$

the $\delta_{s, t}$ and $\delta_{e}$ are depreciation rates of capital, and $\phi_{s}$ and $\phi_{e}$ are capital adjustment cost parameters. Because of variable capital utilization, the depreciation rate on the capital used for capital services is a function of the capital utilization rate so that:

$$
\delta_{s, t}=\delta T_{t}^{\eta}
$$

with $\delta$ being a constant, and $\eta(1<\eta)$ a utilization parameter. Note that depreciation is convex in the utilization rate. Thus an increase in utilization raises depreciation, and successive increases raise depreciation by a larger and larger increment. 


\section{$2.2 \quad$ Firms}

There is one representative final goods firm which stands in for many firms. This firm produces final goods $\left(Y_{t}\right)$ by combining capital services $\left(K S_{t}\right)$ and labor to maximize profit using Cobb-Douglas technology with $\psi$ denoting the capital services share in production:

$$
Y_{t}=Z_{s, t} K S_{t}^{\psi} N_{t}^{1-\psi}
$$

where $Z_{s, t}$ is an exogenous (aggregate) total factor productivity (TFP) shock that evolves as:

$$
\ln Z_{s, t}=\rho_{s} \ln Z_{s, t-1}+\epsilon_{s, t}
$$

and $\rho_{s}$ captures the persistence of the shock. The innovation $\epsilon_{s, t} \sim$ i.i.d $\mathrm{N}\left(0, \sigma_{s, v}^{2}\right)$, where $\sigma_{s, v}$ denotes the standard deviation. Capital services are a constant elasticity of substitution (CES) composite of the capital stock for use in services and energy $\left(E_{t}\right)$ given by:

$$
K S_{t}=\left[\gamma_{k e}\left(T_{t} K_{s, t}\right)^{\tau_{k e}}+\left(1-\gamma_{k e}\right) E_{t}^{\tau_{k e}}\right]^{\frac{1}{\tau_{k e}}}
$$

in this equation $\gamma_{k e}$ is a capital share parameter, and $\tau_{k e}=\frac{\left(\sigma_{k e}-1\right)}{\sigma_{k e}}$, with $\sigma_{k e}$ the elasticity of substitution between capital and energy. Employment at the final goods firm evolves according to:

$$
N_{t}=\left(1-\delta_{n}\right) N_{t-1}+H_{t}
$$

with $H_{t}$ the fraction of workers hired by the firm. This also implies:

$$
H_{t}=x_{t} U_{t}^{o}
$$

As in Gali (2010), there is a cost-per-hire for the firm $\left(M_{t}\right)$. This cost depends on the job finding rate $\left(x_{t}\right)$ and two parameters $(\Gamma, v)$ and is given by:

$$
M_{t}=\Gamma x_{t}^{v}
$$

Because of the hiring cost and the household's utility cost attached to unemployment, there is a surplus associated with employment. The surplus is split between the consumer and firm according to a Nash bargaining protocol each period. Specifically, the firm and each of its workers determine the wage each period by solving:

$$
\max _{w_{t}} S_{s, t}^{\omega} S_{c, t}^{1-\omega}
$$

where $S_{s, t}$ is the surplus of the final goods firm, $S_{c, t}$ is the consumer's surplus, and $\omega$ is the relative bargaining power of firms versus workers. This problem is subject to the definitions of surplus each period, which are outlined in appendix 1. 
Energy is produced by another profit-maximizing stand-in firm, through a CES combination of capital and an energy resource aggregate $\left(R_{t}\right)$ :

$$
E_{t}=\left[\gamma_{k r} K_{e, t}^{\tau_{k r}}+\left(1-\gamma_{k r}\right) R_{t}^{\tau_{k r}}\right]^{\frac{1}{\tau_{k r}}}
$$

the parameters in this equation have an analogous interpretation as in equation (11). The energy resource aggregate is formed through a CES combination of natural gas and other primary energy resources besides natural gas, each of which is in fixed supply:

$$
R_{t}=\left[\gamma_{g o}\left(Z_{g, t} N G_{t}\right)^{\tau_{g o, t}}+\left(1-\gamma_{g o}\right) O_{t}^{\tau_{g o}}\right]^{\frac{1}{\tau_{g o}}}
$$

the parameters in this equation have an analogous interpretation as in equation (11) as well. This equation has a shock to the fixed natural gas supply $\left(Z_{g, t}\right)$ which evolves as:

$$
\ln Z_{g, t}=\rho_{g} \ln Z_{g, t-1}+\epsilon_{g, t}
$$

and $\rho_{g}$ captures the persistence of the shock. The innovation $\epsilon_{g, t} \sim$ i.i.d $\mathrm{N}\left(0, \sigma_{g, v}^{2}\right)$, where $\sigma_{g, v}$ denotes the standard deviation. Define $\tau_{g o}=\frac{\left(\sigma_{g o}-1\right)}{\sigma_{g o}}$, with $\sigma_{g o}$ the elasticity of substitution between natural gas and other primary energy resources. The optimality conditions and equilibrium definition for the model are in appendix 1.

\subsection{Calibration}

The model parameters are given standard values, calibrated to match stylized facts in the data, and computed using the simulated method of moments. In particular, the CRRA parameter $\left(\sigma_{c}\right)$, discount factor $(\beta)$, and final goods capital share $(\psi)$ take standard values for a quarterly model of $1.5,0.99$, and 0.36 , respectively. The depreciation parameter in production of energy $\left(\delta_{e}\right)$ also has the standard value of 0.025 . The depreciation rate in final goods production $\left(\delta_{s}\right)$ is chosen so that the steady-state capital to output ratio is 12 , consistent with the calibration in Arora and Gomis-Porqueras (2011). When variable capital utilization is added to the model, the steady state level of $\delta_{s, t}$ is chosen so that the steady-state capital to output ratio is 12 . In this case $\eta$ is chosen so that the steady state capital utilization rate $(T)$ is 0.80 , which is the U.S. average since 1967 .

The size of each fixed factor is set in the baseline model so that other primary energy sources $\left(O_{t}\right)$ are three times larger than natural gas resources $\left(N G_{t}\right)$. This ratio reflects the fact that natural gas currently accounts for about $25 \%$ of U.S. primary energy (see the 2011 EIA Annual Energy Review for more information, particularly Figure 2.0). These same fixed values are used in all subsequent variations. The capital share parameter on capital services $\left(\gamma_{k e}\right)$ is chosen so that energy is $4 \%$ of value added. This ratio is calculated based on the BEA's KLEMS tables with data from 1998-2011 (pre-1998 is unavailable in this form due to a NAICS revision), by taking the ratio of energy inputs in all industries and U.S. GDP. The natural gas share parameter on energy resource production $\left(\gamma_{g o}\right)$ is chosen so that natural gas is $1 \%$ of value added, or a quarter of energy production as in the Annual Energy Review.

The parameter $\xi$ is set at 0.5 , which implies a standard Frisch elasticity of 2 . In the baseline model the other labor parameter, $\xi_{0}$, is chosen so that labor supply is 0.33 of available time. 
When unemployment is added to the model this parameter is chosen so that $N_{t}$ is 0.59 , reflecting the average share of U.S. employment since 1947. The separation rate $\left(\delta_{n}\right)$ and labor disutility parameter $(\kappa)$ come from matching the average U.S. unemployment rate since 1947 of $5.8 \%$ (this requires setting both $U$ and the labor force participation rate, $N+U$ ). As in Gali (2010), the Nash parameter $(\omega)$ is set equal to 0.5 .

In order to simulate recent U.S. natural gas production trends, the volatility of the natural gas supply shock $\left(\sigma_{v, g}\right)$ is set so that $N G_{t}$ increases instantaneously by $5 \%$. This is the U.S. average annualized marketed natural gas production increase since 2007 each quarter, the beginning of the shale gas revolution. In addition, when investment adjustment costs are used for sensitivity analysis in the models, the values are set by matching the absolute standard deviation of U.S. GDP (0.016) since $1947 .^{3}$

The remainder of parameters in the model are determined by the simulated method of moments as in Bodenstein et al. (2011). The exact values are summarized in panel (b) of Table 1 in appendix 2. The parameter values include the share of capital in energy resource aggregate production $\left(\gamma_{k r}\right)$, two parameters on the hiring cost $(v$ and $\Gamma$ ), the elasticity of substitution between capital and energy $\left(\sigma_{k e}\right)$ the elasticity of substitution between capital and the energy resource aggregate $\left(\sigma_{k r}\right)$, the elasticity of substitution between primary energy sources $\left(\sigma_{g_{0}}\right)$, the first-order autocorrelations on each shock process $\left(\rho_{s}\right.$ and $\left.\rho_{g}\right)$, and the volatilities of the TFP process $\left(\sigma_{v, s}\right)$.

Each parameter value is computed by minimizing the square of the distance between simulated model moments and those observed in the sample data. ${ }^{4}$ The relevant metric is calculated using the standard deviations, standard deviations relative to output, and first-order autocorrelations of U.S. GDP, consumption, investment, hours (baseline model), employment rate (full model), energy production, capacity utilization (full model), and the unemployment rate (full model). ${ }^{5}$ Each of the simulated values are normalized by scaling by the size of the corresponding statistic in the data as in Bodenstein et al. (2011).

A solution to the model is approximated using standard techniques. The values for each endogenous variable in the deterministic steady state are first calculated, and model equations are then log-linearized around these steady state values. Finally, this system of log-linear equations is solved using the method of undetermined coefficients, as in Uhlig (1999). None of the results considered are filtered or transformed in any manner, as they are stationary by construction.

\section{Results}

Impulse responses of select macroeconomic aggregates are first used in this section to assess the impact of various shocks on the baseline model and the full model with variable capital utilization and unemployment. The next section shows that the impacts of natural gas supply shocks can be

\footnotetext{
${ }^{3}$ This is based on the cyclical component of the H-P filtered real GDP series from FRED (GDPC96). The smoothing parameter has a value of 1600 .

${ }^{4}$ The moments are based on the cyclical component of each H-P filtered series with a smoothing parameter of 1600. Where appropriate, the monthly series are first aggregated to quarterly by taking an average.

${ }^{5}$ GDP (GDPC96), consumption (PCECC96), investment (GPDIC96), hours (HOANBS), the capacity utilization rate (TCU), and the unemployment rate (UNRATE) are from FRED. The employment rate is calculated by subtracting the unemployment rate (UNRATE) from the labor force participation rate (CIVPART). Total U.S. energy production is taken from the EIA's monthly energy review.
} 
magnified if there are subsequent rises in either the substitutability of primary energy resources or total factor productivity. The final section concludes by analyzing the importance of investment or hiring costs in the responses to natural gas supply shocks. All of the impulse responses are plotted in Figures 1-3 of appendix 2.

\subsection{TFP Shock}

Figure 1 shows responses from a shock to TFP $\left(Z_{s, t}\right)$ on final goods production in the baseline model and the full model with variable capital utilization and unemployment. This shock clearly highlights some differences between each of the models. The top-left panel shows that GDP in the baseline model responds in a similar manner to standard closed economy real-business cycle models [see e.g. Figure 10 of King and Rebelo (1999)], although the initial magnitude is somewhat smaller. Adding under-utilized capital and labor amplifies the initial impacts on output, but has a slightly different shape. GDP in the full model falls off faster than in the baseline case even though it rises by a greater amount initially. This is because GDP in either model follows the shape of investment, which is shown in the middle-left panel.

With the full model investment rises over 5\% instantaneously, while it is about $3 \%$ higher in the baseline variant. Higher hours in the baseline model and employment in the full model also help to raise GDP, as shown in the middle-right panel. The percentage change in employment is proportionately greater than the percentage increase in hours, which also helps to amplify the output response of the full model. Consumption increases by a greater amount in the baseline model, as shown in the top-right panel. This is because the marginal product of capital rises by a larger amount in the full model, leading to greater initial investment and less initial consumption.

One reason for this greater rise in capital's marginal product is that the capital utilization rate increases, as shown in the bottom-right panel. The bottom-left panel displays a short increase in the unemployment rate before it sharply falls off and then rises towards the steady state value. This initial rise in unemployment occurs because the percentage increase in the labor force is larger than the percentage increase in employment shown in the middle-right panel.

In summary, the responses to a TFP shock are in-line with standard real business cycle models. Investment is an important driver of GDP growth, and under-utilized capital and labor magnify the various responses to the TFP shock.

\subsection{Natural Gas Supply Shock}

Figure 2 shows responses from a shock to natural gas supply $\left(Z_{g, t}\right)$ in the baseline model and the full model with variable capital utilization and unemployment. Overall, the responses have similar shapes as with a TFP shock, although the magnitude is smaller and there are some individual differences. The top-left panel shows that GDP increases with the natural gas supply shock and then quickly falls over time. The full model has an initial impact that is roughly double that of the baseline model. Both shapes are similar to that of investment, shown in the middle-left panel. Investment increases almost $1 \%$ with under-utilized capital and labor, compared with around $0.4 \%$ in the baseline case. Employment and hours both rise as well, as shown in the middle-right panel.

In the baseline model investment gains occur because greater natural gas production leads to a larger resource aggregate (using the same inputs), which then raises energy production. Higher 
energy production raises the marginal product of capital, which induces more investment and a rise in hours worked (intertemporal substitution of labor). This response is magnified in the case of under-utilized capital and labor. Increasing capital utilization and hiring more workers further raises the marginal product of capital after a natural gas supply shock, which eventually leads to even greater investment. And these hikes in investment follow through into GDP as plotted in the top-left panel. The bottom-panel shows that unemployment and capital utilization exhibit similar patterns as with the TFP shock.

The full model also sees greater GDP rises because of an income effect. The inclusion of additional workers into employment leads to higher overall income, which also raises demand for consumption goods, as displayed in the top-right panel. In the baseline model consumption falls with the natural gas supply shock before rising. This occurs because saving (in the form of capital investment) leaves the consumer better off versus current consumption. This changes in the full model because higher employment leads to greater current consumption from those newly employed.

In summary, responses to the natural gas supply shock lead to small or moderate increases in GDP, with investment an important component of this growth. The impulse responses are magnified by under-utilized capital and labor, and many look similar to those from a standard TFP shock. In quantitative terms, the instantaneous response of GDP ranges from about $0.10 \%$ to $0.30 \%$ (this is an annualized percentage increase). This roughly equates to annual GDP gains of 15-40 billion dollars based on 2011 U.S. GDP (in 2005 dollars). The employment rate increases by up to $0.20 \%$, which is roughly an annual increase of 230,000 jobs (using average 2011 U.S. employment of 131 million and assuming no change in the labor force). Neither of these estimates are insignificant, particularly if they occur over a period of several years, but they are at best moderate rises in terms of the forecasts discussed in the introduction.

\subsection{Multiplying the Economic Impact}

These small to moderate rises are somewhat inconsistent with much of the rhetoric around recent U.S. natural gas production trends. How might natural gas supply shocks have a bigger impact on GDP? One possibility that is specific to the energy sector is currently occurring. As firms become convinced that natural gas supply increases are permanent, they may invest in infrastructure to use this additional natural gas in energy generation. A good example is the construction of electric power plants that depend on natural gas as opposed to those which use coal. In the model, this can be thought of as increasing the degree of substitutability in the aggregation of primary resources.

The top-left panel of Figure 3 displays impulse responses of GDP to natural gas supply shocks when there is also an increase in the elasticity of substitution between primary energy resources $\left(\sigma_{g o}\right)$. The solid line is the baseline simulation with no response of the elasticity, and each subsequent line shows greater impacts on $\sigma_{g o}$. As the response of substitutability increases so do the rises in GDP, although the increments are relatively small between each simulation. The basic idea is that the process of primary energy resources becoming more substitutable leads to investment (and greater hours worked as a result), which increases GDP.

Possibly because it is concentrated in the energy sector, increasing substitutability by itself seems unable to deliver a large magnification of natural gas supply shocks. An alternative is that such supply shocks can lead to broader gains in other sectors as well, that they directly impact on economy-wide productivity. As an example, higher natural gas production has led to lower prices, 
which has fed into lower electricity bills for some U.S. households. If electricity costs remain low for the foreseeable future, battery-powered cars may become competitive with gasoline-based vehicles. The required investments in infrastructure and production facilities to support these new vehicles are enormous, and can be thought of as due to increases in TFP.

The top-right panel of Figure 3 plots the impulse responses of GDP in the baseline model when this also leads to an increase in TFP. The solid line is the baseline simulation with no impact on TFP, and each of the remaining lines increase TFP by different amounts. The responses clearly show that productivity enhancements due to natural gas supply shocks can substantially multiply the economic impacts of these shocks. A supply shock that leads to a $0.5 \%$ rise in TFP can increase GDP instantaneously by nearly $1.0 \%$ in the baseline model, and this is even higher with unemployment and unused capital.

In summary, the economic impacts of natural gas supply shocks can be substantially multiplied if they also result in economy-wide productivity enhancements. For the examples shown GDP increases by $0.10-1.0 \%$, roughly corresponding to $15-130$ billion dollars based on 2011 U.S. GDP. There are also benefits to increased substitution between primary energy resources due to the supply shock, but these are smaller.

\subsection{Reducing the Economic Impact}

While certain factors may increase the economic impact of natural gas supply shocks, there are separate factors that can also work to reduce them. These are grouped here in general terms as investment or hiring costs. Investment costs are those which apply to any changes in the capital stock, and hiring costs are those which make it more expensive for firms to hire workers. In either model, investment costs can be applied to capital in the final goods or energy sectors, whereas hirings costs are only applicable in final goods for the full model.

The bottom-left panel of Figure 3 shows the impulse responses of GDP after a natural gas supply shock in the baseline model with various investment costs. The two larger responses correspond to the baseline model with no adjustment costs, and the case where adjustment costs are applied only to the energy sector. It seems that when applied only to the energy sector, investment costs have little impact on GDP after a natural gas supply shock. The smaller response corresponds to the case with investment costs only in the final goods sector. These do have an impact on the impulse responses of GDP following the supply shock.

The impulse responses indicate that the most important investment costs are those on final goods production. This is because the energy sector is a relatively small share of the economy (and natural gas even smaller still), which means that higher costs of investment in this sector do not have an appreciable impact on aggregate GDP after a natural gas supply shock. Rather, these costs matter more when they show up in the broader economy because the gains from the supply shock mainly take place outside of the natural gas extraction sector (think of distribution, processing, etc.).

Increases in hiring costs in the full model are shown in the bottom-right panel of Figure 3. The GDP responses show a monotonic decline in that greater hiring costs lead to lower GDP responses, as would be expected. The shape of each impulse response is also similar. The take-away from this chart is that anything that makes hiring more difficult in the broader economy can reduce the impact of a natural gas supply shock. This is because less labor can be put to use with capital 
in production, which means that aggregate income is lower, and so is demand for both investment and consumption goods in the overall economy.

In summary, the economic impacts of natural gas supply shocks can also be reduced due to the costs of investment or hiring. In the case of investment costs, the example simulations suggest that GDP gains due to natural gas supply shocks could be reduced by up to one-half. Losses due to hiring costs are smaller, but still reduce GDP gains.

\subsection{How Might Natural Gas Change Aggregate Productivity?}

The various simulations indicate that increases in productivity following natural gas supply shocks help to magnify their economic impacts. In this section I speculate on how important the shale gas revolution may be for economy-wide productivity. The section begins with a brief look at past productivity trends and estimates and concludes with a perspective on how natural gas fits into this narrative.

\subsubsection{Historical Trends}

Table 2 in appendix 2 shows average growth rates in total factor productivity and/or multi factor productivity (MFP) over select periods in the last 120 years. The intervals are based on Gordon (2010), with the second column the adjusted MFP growth rates for the non-farm non-housing business sector. The third column lists MFP growth rates, adjusted for utilization, over the same intervals based on the data series provided by Fernald (2012) for the business sector.

Both of these series show that average increases in U.S. productivity before the early-1970s were higher than those after, although productivity growth rebounded in the years following 1996. In the Gordon (2010) series the fastest rate of annual growth occurred between 1928 and 1950, at $2.35 \%$. This is followed by an average rate of growth of $1.32 \%$ from 1950 to $1964,1.25 \%$ from 1996 to 2007 , and $1.16 \%$ from 1964 to 1972 . The highest average rate of growth in the Fernald (2012) series is between 1950 to 1964 , at $2.18 \%$. This is followed by a $1.65 \%$ average rate of growth from 1964 to $1972,1.10 \%$ from 1996 to 2007 , and $1.06 \%$ from 1972 to 1979.

There is a clear pattern in either series that average economy-wide productivity gains are higher until 1972, fall from 1972-1996, and then rise again after 1996. Gordon (2000) argues that the relatively higher productivity growth before 1972 is due to great inventions in the late-19th and early-20th centuries which transformed everyday life. He groups these into five categories: electricity; the internal combustion engine; petroleum, natural gas, and associated processing; entertainment, communication, and information innovations; and urban sanitation infrastructure. Field (2006) looks at the period from 1919 to 1941 and argues that the rapid productivity growth in this period was driven by a combination of gains in manufacturing productivity and spill-overs from government-financed infrastructure investment to transport, public utilities, and wholesale and retail distribution.

According to Gordon (2000), the revival in productivity growth from 1996 to 2000 was driven by gains in computer hardware, peripherals, and telecommunications equipment, along with associated spill-overs in the manufacturing of durable goods. This is also consistent with Field (2006), who documents that U.S. productivity growth revived after 1995 and credits some of this to information technology and its application in certain industries. Gordon (2010) argues that after the collapse of 
the information technology boom in 2000 productivity growth continued at a higher rate than the 1972 to 1996 period because of aggressive cost-cutting by firms and lagged responses to information technology advances from the 1990s.

In general, it appears that the rapid and long-lived U.S. productivity growth before 1972 was broad-based across industries, and the result of many different innovations. The revival after 1996, at slower growth rates than before 1972, appears to have been concentrated in specific information technology-producing and using sectors. And it is unclear how long this revival may last.

\subsubsection{The Impact of Natural Gas on Future Productivity}

Given this history, how important might the shale gas revolution be for future U.S. productivity growth? It is extremely unlikely that the innovations and technologies which follow because of increased U.S. natural gas production and a larger resource base will have the transformative implications of the great inventions specified by Gordon (2000). I would expect that the resultant productivity gains will be smaller and last a shorter amount of time than in those earlier episodes simply because they will not be as important.

The period from 1995 to 2000 is a better starting point for comparison. This is because the advances in productivity were concentrated in the information technology industry and subsequently spilled over to other sectors, notably manufacturing. In the case of natural gas, the technological improvements have been concentrated in the mining sector (oil and gas extraction). Table 3 lists some industries where there have already been or might potentially be productivity spill-overs due to these technological improvements. These include agriculture and related industries, mining, utilities, construction, manufacturing, and transportation and warehousing. These sectors have accounted for nearly $28 \%$ of private sector value added on average since 1998 .

Field (2006) divides the non-farm U.S. economy between manufacturing, wholesale and retail trade, and all other industries. He then argues that if information technology was able to account for all productivity gains in manufacturing and a third of productivity gains in the remainder of industries it could account for about $60 \%$ of MFP growth in the 1995-2000 period, or about $0.70 \%$. My industry breakdown in Table 3 is similar in size to the sum of manufacturing and wholesale and retail trade. On average since 1998 the sectors in Table 3 are $27.8 \%$ of private sector value added, while manufacturing and wholesale and retail trade are $28.7 \%$ of private sector value added.

Will the shale gas revolution lead to productivity gains in the sectors listed in Table 3 which compare with those driven by information technology? It seems unlikely that unconventional natural gas will be as important for the entire manufacturing industry as information technology. However, in comparing the differences between the 1930s and 1990s in terms of productivity advances, Field (2006) claims that the 1990s lacked the broad based and very rapid advances in transportation and public utilities of the 1930s. This is one area where shale gas could have an enormous impact on productivity, for example in advancing automobile technology, or in distributed generation of electricity, and even with basic energy infrastructure such as power lines.

Given the nature and structure of recent advances in unconventional natural gas production, the information technology-led productivity growth provides a good starting point for comparison. Although information technology is used throughout many different sectors, the productivity gains have been relatively concentrated in manufacturing and retail and wholesale trade. Natural gas is less important across many different sectors, but makes possible productivity gains that are 
more broad based. The magnitude of broad-based gains will eventually determine if natural gas has a larger or smaller impact on economy-wide productivity than recent advances in information technology.

\section{Implications and Conclusion}

In this paper I evaluate the macroeconomic impacts of recent and forecast U.S. natural gas trends. My starting point for comparison are predictions about the potential economic benefits of greater natural gas production and a larger resource base. I take a different approach and construct a general equilibrium model, and then extend it with under-utilized capital and unemployment. The results can be summarized in the following four statements:

1. Each of the two models show small-to-moderate GDP gains due to increases in natural gas supply.

2. The economic impacts of natural gas supply shocks can be magnified if there are subsequent rises in economy-wide productivity.

3. Investment and hiring costs in the broader economy can reduce the economic benefits of natural gas supply increases.

4. The period from 1995 to 2000 , where productivity growth was driven by information technology, is a good starting point for comparing how productivity may evolve because of natural gas.

Several important issues that deserve further study are beyond the scope of this paper. The first are international issues in natural gas and investment. The shale gas revolution makes U.S. natural gas exports possible (subject to regulatory approval) while also increasing the amount of natural gas that might be extracted outside of the U.S. In the simulations investment is an important component of GDP growth, and it is assumed that all firm investment takes place domestically. This will not necessarily be the case, and firm decisions on where to invest may be important.

I abstract from important regulatory issues surrounding unconventional natural gas production, its transport, and its use of water. These are likely to impact the pace of increases in U.S. natural gas extraction, as well as where it might take place. Finally, the specific details of how the shale gas revolution might impact total factor productivity and for how long has not been addressed here.

\section{References}

Arora, Vipin and Jozef Lieskovsky, "Natural Gas and U.S. Economic Activity," Working Paper 42659, MPRA 2012.

- and Pedro Gomis-Porqueras, "Oil Price Dynamics in a Real Business Cycle Model," Working Paper 2011-17, CAMA 2011.

Bodenstein, Martin, Christopher J. Erceg, and Luca Guerrieri, "Oil Shocks and External Adjustment," Journal of International Economics, 2011, 83 (2), 168-184. 
CitiGPS, "Energy 2020: North America the New Middle East?," 2012.

Fernald, John, "A Quarterly, Utilization-Adjusted Series on Total Factor Productivity," Working Paper 2012-19, Federal Reserve Bank of San Francisco 2012.

Field, Alexander J., "Technical Change and U.S. Economic Growth: The Interwar Years and the 1990s," in Paul Rode and Gianni Toniolo, eds., Undestanding the 1990s: The Economy in a Long Run Perspective, Cambridge University Press, 2006, pp. 89-117.

Gali, Jordi, "Monetary Policy and Unemployment," Working Paper 15871, NBER 2010.

Gordon, Robert J., "Does the 'New Economy' Measure up to the Great Inventions of the Past?," Journal of Economic Perspectives, 2000, 14 (4), 49-74.

_ , "Revisiting U.S. Productivity Growth Over the Past Century With a View of the Future," Working Paper 15834, NBER 2010.

Greenwood, Jeremy, Zvi Hercowitz, and Gregory W. Huffman, "Investment, Capacity Utilization, and the Real Business Cycle," The American Economic Review, 1988, 78 (3), 402417.

ICF, "Oil and Gas Technology Innovation: How it is Spurring U.S. Economic Growth," 2012.

IHS, "The Economic and Employment Contributions of Shale Gas in the United States," 2011.

_, "The Economic and Employment Contributions of Unconventional Gas Development in State Economies," 2012.

King, Robert G. and Sergio T. Rebelo, "Resusciting Real Business Cycles," in J.B. Taylor and M. Woodford, eds., Handbook of Macroeconomics, 1st ed., Vol. 1, Elsevier, 1999, chapter 14, pp. $927-1007$.

Kinnaman, Thomas C., "The Economic Impact of Shale Gas Extraction: A Review of Existing Studies," Other Faculty Research and Publications Paper 5, Bucknell University 2010.

Kliesen, Kevin L., "Rising Natural Gas Prices and Real Economic Activity," Federal Reserve Bank of St. Louis Review, 2006, 88 (6), 511-526.

PWC, "Shale Gas: A Renaissance in U.S. Manufacturing?," 2011.

_ , "Shale Gas: Reshaping the U.S. Chemicals Industry," 2012.

Uhlig, Harald, "A Toolkit for Analysing Nonlinear Dynamic Stochastic Models Easily," in Ramon Marimon and Andrew Scott, eds., Computational Methods for the Study of Dynamic Economies, OUP, 1999, pp. 30-61. 


\section{Appendix 1: Optimality Conditions and Equilibrium}

The consumer problem yields the following optimality conditions:

$$
\begin{gathered}
\frac{1}{C_{t}}=\mathbb{E}_{t}\left\{\frac{\beta}{C_{t+1}}\left[r_{s, t+1} T_{t+1}+\left(1-\delta_{s, t}\right)\right]\right\} \\
\frac{1}{C_{t}}=\mathbb{E}_{t}\left\{\frac{\beta}{C_{t+1}}\left[r_{e, t+1}+\left(1-\delta_{e}\right)\right]\right\} \\
r_{s, t}=\eta \delta T_{t}^{\eta-1} .
\end{gathered}
$$

the first two equations state that any reduction of consumption today, which is used for investment, must be equal to the discounted gain from the return on that investment. The third equates the benefit from utilizing an additional unit of capital in producing final goods (its rate of return) to the cost (a higher depreciation rate). In terms of production, at the lowest level the amount of natural gas and other primary energy which can be used in production are fixed:

$$
\begin{gathered}
N G_{t}=\overline{N G} \\
O_{t}=\bar{O}
\end{gathered}
$$

the price of each fixed factor comes from the next level up when choosing how much of the energy resource aggregate to produce:

$$
\begin{gathered}
p_{g, t}=\frac{p_{r, t} \gamma_{g o} R_{t}\left(Z_{g, t} N G_{t}\right)^{\tau_{g o}-1}}{R^{\tau_{g o}}} \\
p_{o, t}=\frac{p_{r, t}\left(1-\gamma_{g o}\right) R_{t} O_{t}^{\tau_{g o}-1}}{R^{\tau_{g o}}}
\end{gathered}
$$

where the resource aggregate price is derived based on the firm's optimal energy production:

$$
p_{r, t}=\frac{p_{e, t}\left(1-\gamma_{k r}\right) E_{t} R_{t}^{\tau_{k r}-1}}{E^{\tau_{k r}}}
$$

and the rate of return on capital for use in energy production comes from the same problem:

$$
r_{e, t}=\frac{p_{e, t} \gamma_{k r} E_{t} K_{e, t}^{\tau_{k r}-1}}{E^{\tau_{k r}}}
$$

similarly, the price of energy depends on the firm's capital services choice:

$$
p_{e, t}=\frac{\psi\left(1-\gamma_{k e}\right) Y_{t} E_{t}^{\tau_{k e}-1}}{K S^{\tau_{k e}}}
$$


and the rate of return on final goods capital comes from the same problem:

$$
r_{s, t}=\frac{\psi \gamma_{k e} Y_{t}\left(T_{t} K_{s, t}\right)^{\tau_{k e}-1}}{K S^{\tau_{k e}}}
$$

the firm's choice of labor weights the costs and benefits of hiring an additional worker:

$$
\frac{(1-\psi) Y_{t}}{N_{t}}=w_{t}+M_{t}-\beta \mathbb{E}_{t}\left\{\frac{C_{t}}{C_{t+1}}\left(1-\delta_{n}\right) M_{t+1}\right\}
$$

The definitions of surplus used in the Nash bargaining problem are (see Gali (2010) for derivations):

$$
\begin{gathered}
S_{s, t}=M_{t} \\
S_{c, t}=w_{t}-\kappa \xi_{0} L^{\xi} C_{t}+\left(1-\delta_{n}\right) \beta \mathbb{E}_{t}\left\{\frac{C_{t}}{C_{t+1}} S_{c, t+1}\right\}
\end{gathered}
$$

The bargaining problem also yields two equations. The first specifies the wage as a weighted average between the firm's marginal product and the consumer's marginal rate of substitution:

$$
w_{t}=\frac{\omega(1-\psi) Y_{t}}{N_{t}}+(1-\omega) \xi_{0} L^{\xi} C_{t}
$$

the other equation from the Nash bargaining solution is a participation condition:

$$
(1-\omega) \kappa \xi_{0} L^{\xi} C_{t}=\omega \frac{x_{t}}{1-x_{t}} M_{t}
$$

The final equation specifies firm profits as the difference between total revenues and total costs in the production of final goods:

$$
\pi_{t}=Y_{t}-w_{t} N_{t}-r_{s, t} K_{s, t}-p_{e, t} E_{t}-M_{t} H_{t}
$$

The equilibrium for this economy is a process of prices $\left\{p_{e, t}, p_{r, t}, p_{g, t}, p_{o, t}, r_{s, t}, r_{e, t}, w_{t}\right\}_{t=0}^{\infty}$, a process of allocations $\left\{C_{t}, I_{s, t}, I_{e, t}, K_{s, t}, K_{e, t}, K S_{t}, E_{t}, R_{t}, N G_{t}, O_{t}, Y_{t}, N_{t}, L_{t}, U_{t}, U_{t}^{0}, H_{t}, x_{t}, M_{t}, \pi_{t}\right\}_{t=0}^{\infty}$, a process of utilization and depreciation rates $\left\{T_{t}, \delta_{s, t}\right\}_{t=0}^{\infty}$, and exogenous processes $\left\{Z_{s, t}, Z_{e, t}, \sigma_{g o, t}\right\}_{t=0}^{\infty}$ such that (i) taking all prices save the wage as given, households maximize utility; (ii) taking all prices save the wage as given, firms maximize profits; (iii) all markets clear; and (iv) each household's budget constraint is met.

\section{Appendix 2: Tables and Figures}




\begin{tabular}{clcc}
\hline Parameter & Description & Baseline & Full Model \\
\hline$\beta$ & Discount factor & 0.990 & 0.990 \\
$\sigma_{c}$ & CRRA & 1.50 & 1.50 \\
$\delta_{s}$ & Depreciation, Final Goods & 0.018 & 0.026 \\
$\delta_{e}$ & Depreciation, Energy & 0.025 & 0.025 \\
$\phi_{s}$ & Capital adjustment costs, Final Goods & 0,1 & - \\
$\phi_{e}$ & Capital adjustment costs, Energy & 0,1 & - \\
$\xi$ & Labor supply parameter & 0.50 & 0.50 \\
$\xi_{0}$ & Labor supply parameter & 2.03 & 1.81 \\
$\kappa$ & Labor disutility parameter & - & 0.069 \\
$\psi$ & Capital services share of final goods prod & 0.36 & 0.36 \\
$\gamma_{k e}$ & Capital share of energy prod & 0.999 & 0.999 \\
$\gamma_{g o}$ & NG share of primary energy & 0.105 & 0.458 \\
$\eta$ & Capital utilization parameter & - & 1.55 \\
$\omega$ & Nash bargaining parameter & - & 0.5 \\
$\sigma_{v, g}$ & Volatility of NG supply shock & 0.05 & 0.05 \\
$N G$ & Fixed stock of NG & 5.00 & 5.00 \\
$\bar{O}$ & Fixed stock of Other Resources & 1.67 & 1.67 \\
\hline
\end{tabular}

(a) Calibrated Based on Stylized Facts

\begin{tabular}{clcc}
\hline Parameter & Description & Baseline & Full Model \\
\hline$\gamma_{k r}$ & Capital share of energy resources & 0.110 & 0.265 \\
$v$ & Parameter on hiring cost & - & 1.00 \\
$\Gamma$ & Parameter on hiring cost & - & $0.02,0.2,2,20$ \\
$\delta_{n}$ & Separation rate & - & 0.570 \\
$\sigma_{k e}$ & Elasticity of substitution, capital and energy & 0.272 & 0.310 \\
$\sigma_{k r}$ & Elasticity of substitution, capital and resource & 0.470 & 0.260 \\
$\sigma_{g o}$ & Elasticity of substitution, NG and other & 0.354 & 0.500 \\
$\rho_{s}$ & First-order autocorrelation of technology shock & 0.930 & 0.864 \\
$\rho_{g}$ & First-order autocorrelation of NG supply shock & 0.757 & 0.617 \\
$\sigma_{v, s}$ & Volatility of technology shock & 0.005 & 0.006 \\
\hline
\end{tabular}

(b) Calibrated Using Simulated Method of Moments

Table 1: Model Parameter Values 


\begin{tabular}{lcc}
\hline Period & Gordon (2010) & Fernald (2012) \\
\hline $1891-1913$ & $1.06 \%$ & - \\
$1913-1928$ & $0.89 \%$ & - \\
$1928-1950$ & $2.35 \%$ & - \\
$1950-1964$ & $1.32 \%$ & $2.18 \%$ \\
$1964-1972$ & $1.16 \%$ & $1.65 \%$ \\
$1972-1979$ & $0.65 \%$ & $1.06 \%$ \\
$1979-1988$ & $0.22 \%$ & $0.70 \%$ \\
$1988-1996$ & $0.18 \%$ & $0.74 \%$ \\
$1996-2007$ & $1.25 \%$ & $1.10 \%$ \\
\hline
\end{tabular}

Table 2: Comparison of adjusted MFP (TFP) growth rates over select periods. The second column is taken from Table 8 of Gordon (2010) and the third is based on Fernald (2012).

\begin{tabular}{lcc}
\hline NAICS Code & Industry Title & Average Share \\
\hline 11 & Agriculture, forestry, fishing, and hunting & $1.19 \%$ \\
21 & Mining & $1.65 \%$ \\
22 & Utilities & $2.06 \%$ \\
23 & Construction & $5.08 \%$ \\
$31-33$ & Manufacturing & $14.5 \%$ \\
$48-49$ (save 491) & Transportation and warehousing & $3.37 \%$ \\
& Total & $27.8 \%$ \\
\hline
\end{tabular}

Table 3: Average share of private industry value added for select industries from 1998-2011, based on BEA industry accounts data. 


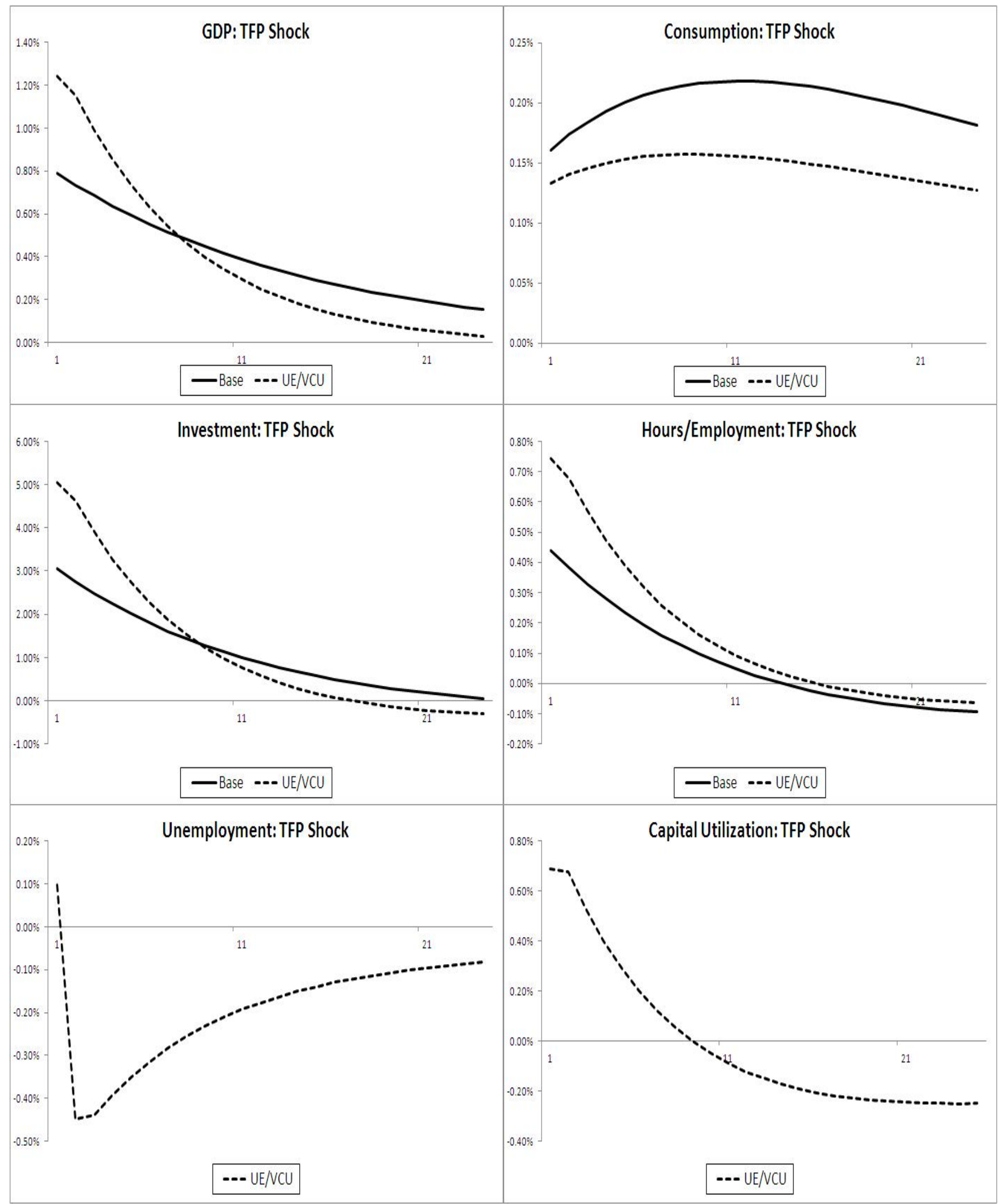

Figure 1: Response of the different models to a one-standard deviation shock in total factor productivity on final goods production. 


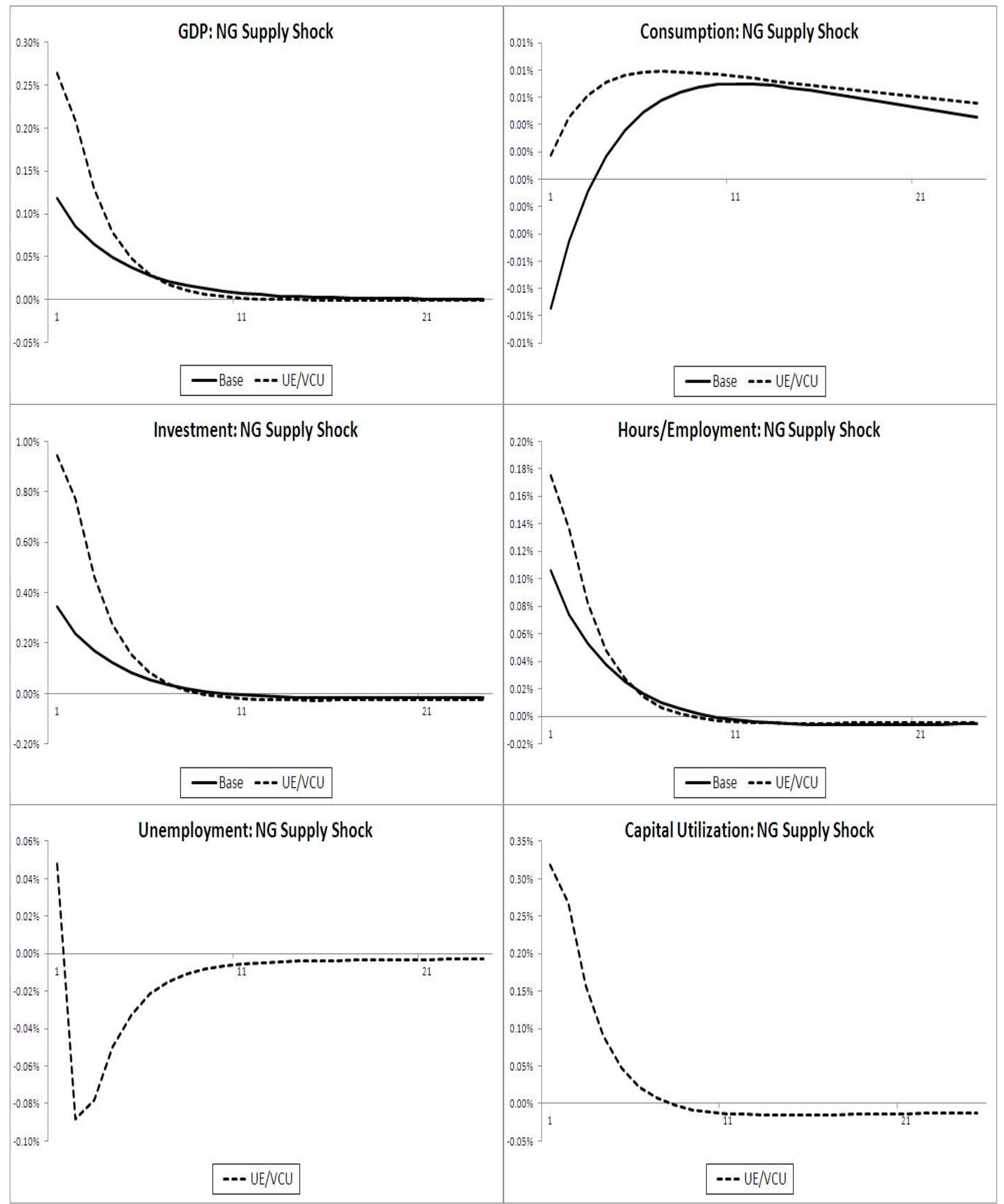

Figure 2: Response of the different models to a one-standard deviation shock in natural gas production. 


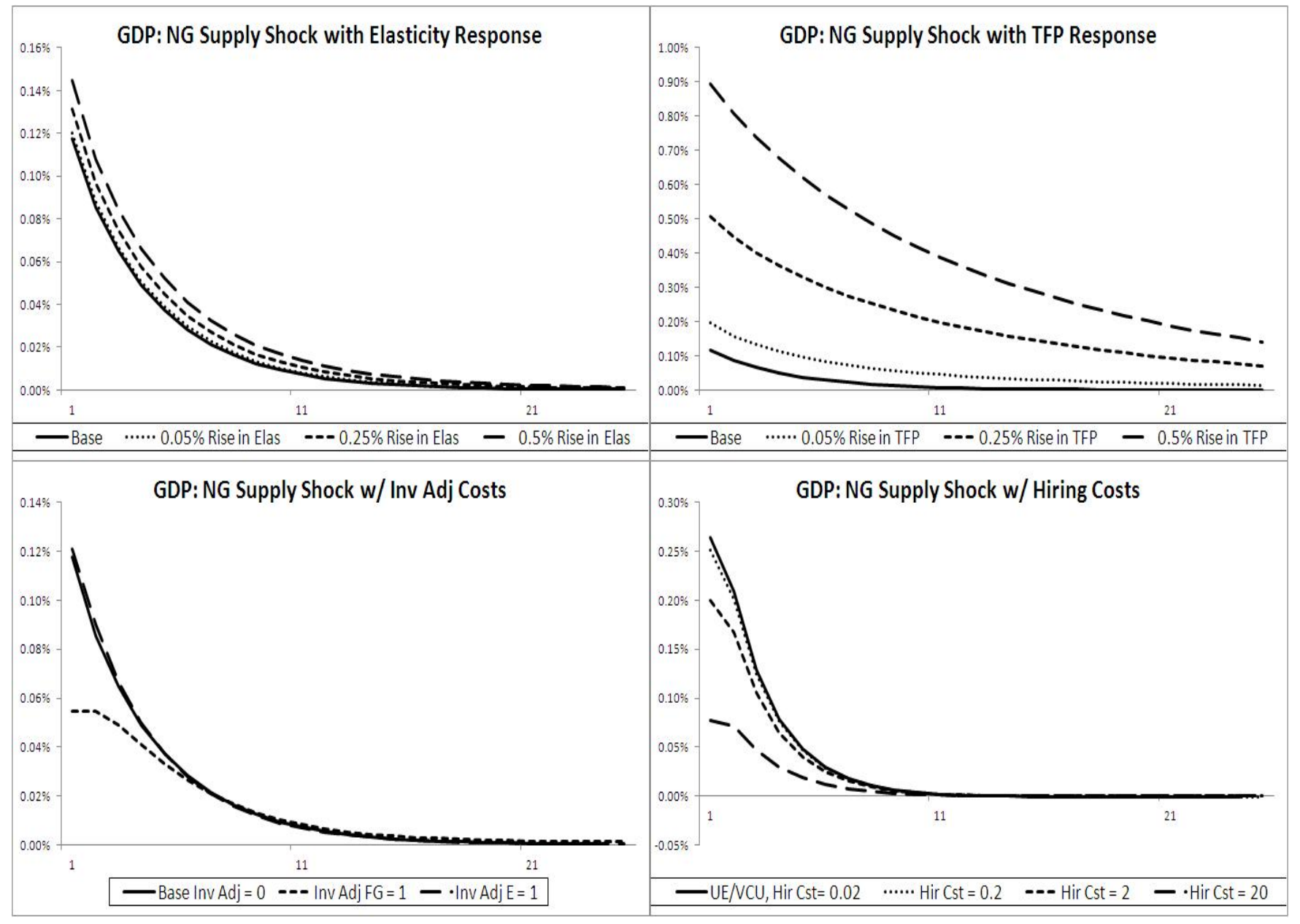

Figure 3: Top-left: Response of the baseline model to natural gas supply shocks which subsequently impact the elasticity of substitution between primary energy sources by varying amounts. Top-right: Response of the baseline model to natural gas supply shocks which subsequently impact TFP by varying amounts; Bottom-left: Response of the baseline model to a natural gas supply shock with different investment adjustment costs; Bottom-right: Response of the full model to a natural gas supply shock with various hiring costs. 